\title{
Community based breeding program for improve goat production in Liberia
}

\begin{abstract}
To effectively allow for ownership and sustainability of genetic improvement programs, Community Based Breeding Programs (CBBP) is designed. Village/Community based breeding programs are organized breeding activities that are planned, designed and implemented by smallholder farmers individually or in cooperation with technical stakeholders to effect genetic improvement within their livestock. In developing economies, livestock improvement is achieved through an aggressive involvement of livestock owners. In most cases, these farmers are resource poor and marginalized. Community based breeding program was organized with focus on indigenous breeds suited to smallholder conditions. The CBBP will serve as a working model for Animal Genetic Resource management in Liberia to increase productivity and improve livelihood of goat farmers. The CBBP is envisaged to increase the productivity and profitability of indigenous West Africa Dwarf goats of Liberia without undermining their resilience and genetic integrity, and without expensive interventions. The CBBP was a component under the project, survey and characterization of livestock breeds and their production system in Liberia for the development of a national strategy and action plan for animal genetic resources. The Project was supported by FAO under the technical cooperation program in Liberia. The establishment of the CBBPs for goat farmers in Liberia was very successful and should be a prototype of what is possible when all partners acknowledged the need for livestock producers to take responsibility of their own resource.
\end{abstract}

Volume I Issue 5 - 2018

\author{
Arthur Bob Karnuah,' Gregory Dunga,' \\ Thomas Rewe ${ }^{2}$ \\ 'Department of Livestock and Fishery, Central Agricultural \\ Research Institute, Liberia \\ ${ }^{2}$ Department of Animal Science, Pwani University, Kenya \\ Correspondence: Arthur Bob Karnuah, Department of \\ Livestock and Fishery, Central Agricultural Research Institute, \\ National Project Coordinator, ECTAD/FAO Liberia Food \& \\ Agriculture Organization (FAO), One UN Building, Pan African \\ Plaza, $8^{\text {th }}$ Floor, I $^{\text {st }}$ Street, Sinkor, Liberia \\ Email akarnuah9@gmail.com
}

Received: September 14, 2018 | Published: October 02, 2018

Keywords: community, based, breeding, program, goats, nucleus

\section{Introduction}

A situational analysis of livestock production in Liberia brings to light the potential of Liberia, despite the pitfalls that must be overcome. The current situation with livestock production resulted from a battery of contributing factors. Andrews ${ }^{1}$ indicates that livestock production has been the least prioritized bureau within the Ministry of Agriculture with an estimated 2 million ha of pastureland while accounting for a humble figure of $14 \%$ agricultural GDP. However, the consequences of this study require that livestock production be prioritized for livelihood creation. The major findings revealed that the livestock population in Liberia is increasing, with little input on farmer capacity building. The recommendations highlighted key platforms for change in the livestock sector, to prioritize actions on livestock development, enhance capacity of stakeholders, strengthening the actors and championing collective action. By 2011, action began in major fronts in the livestock sector, specifically goat production. The USAID funded Feed and Enterprise Development ${ }^{2}$ project targeting major cash crops and goats injected much needed visibility of the livestock sector in Liberia. ${ }^{2}$ The USDALand O" Lakes Goat Project aimed at revitalizing the livestock sector by introducing goat production, and improving meat processing safety and standards also contributed to the stratification of the meat value chain. In 2016, a state of the $\operatorname{art}^{3}$ slaughter house was build. The pillars for sustainability of the meat value chain include constant supply of quality meat. Quality is a function of breeds and breeding. A natural progression towards engaging the meat producers to benefit from the emerging value chain is to encourage quantity and quality meat production. The Goat farmers, in this particular case, have been organized and are being trained to accommodate this goal and benefit from the meat value chain. A simple Goat project to increase both numbers and performance is therefore envisaged.

In developing economies, livestock improvement is achieved through an aggressive involvement of livestock owners. In most cases, these farmers are resource poor and marginalized. To effectively allow for ownership and sustainability of genetic improvement programmes, Community Based Breeding Programs (CBBP) are designed. A good example is the Ethiopia Sheep and Goat Productivity Improvement Program ${ }^{4}$ that launched the village breeding program. ${ }^{4}$ Village/Community based breeding programs are organized breeding activities that are planned, designed and implemented by smallholder farmers individually or in cooperation with technical stakeholders to effect genetic improvement within their livestock.

The difficulty in readily accessing good breeds and quality genetic stock in Liberia has created a greater need for the establishment of a sustainable breeding program that is extensive/low input, small scale, and community owned. The community based breeding program focuses on indigenous breeds suited to smallholder conditions. The CBBP serves as a working model for Animal Genetic Resource management in Liberia to increase productivity and improve livelihood of livestock keepers. The CBBP is envisaged to increase the productivity and profitability of indigenous breeds without undermining their resilience and genetic integrity, and without expensive interventions. It is upon this background that the first CBBP with specific reference to Goat production in Liberia was developed. The objective of the CBBP program is to improve productivity and income of small scale resource poor goat producers in Liberia by providing access to improved animals that respond to improved feeding and management, while facilitating and targeting specific market opportunity. 


\section{The project strategy}

\section{Activity I: Characterization and Identification of target breed of goat}

The characterization and identification of goat farming communities-previously organized by Food Enterprise DevelopmentUSAID $^{2}$ facilitated the selection and recruitment of Goat farming communities into the CBBP with the West Africa Dwarf Goat (WADG) as the selected breed. Goat farmers in three counties (Bong, Nimba and Bassa) were pre-selected for assessment and possible recruitment into the proposed CBBP. In each of these Counties, two farmer groups were recruited upon satisfying the selection criteria for participation in the proposed CBBP. The survey focused on cooperation, motivation and willingness among members of the goat farming community group.

\section{Activity II: Designing CBBP operating system and implementation strategy}

\section{Participatory approaches towards designing the breeding programme}

Farmers were involved in identifying appropriate breeding objectives and selection criteria for goats through capacity building training modules. Training included village breeding programs operationalization, goat management, breeding objective development, identification and recording of goats and goat performance, selection and mating as well as group dynamics. Three farmers from each selected farmer group representing the three counties were assembled for training and in the setting up of the CBBP structure at the Central Agricultural Research Institute (CARI).

\section{Activity III: Purchase of inputs (bucks and veterinary materials)}

Purchase of breeding bucks and veterinary materials was envisaged in support of the breeding programme. Farmers forfeiting opportunity to sell quality bucks for meat in the live goat markets would be compensated through the buck purchase program to sustain the CBBP. Animal health as a pillar of any livestock production enterprise was supported through the purchase of veterinary drugs.

\section{Activity IV: Sustainability protocol}

The institutional support to the CBBP included capacity development and technical assistance as well as monitoring the CBBP program and implementing modification as need arises. The central Agricultural Research Institute (CARI) spearheaded the role.

\section{Field visits to goat farmers associations}

Following Muller et al. ${ }^{5}$ the strategy to effectively design structure and organization of the CBBP require full participation of the main stakeholders, the farming community in understanding their production system and defining appropriate breeding objectives. The field visits to the potential candidate farmer groups for recruitment into the CBBP had the following objectives:

a. To evaluate the assessment report and assess progress to date.

b. To discuss Goat quality, its preservation and multiplication.

c. To introduce the concept of breeding and breeding objective. d. To score farmer group preparedness for the CBBP training workshop.

To achieve these objectives, a focused group discussion incorporating members of the farmer groups was organized during the field visits. The major highlights of these visits include the fact that the Goat structures and farm sites originally developed by the FED projects are generally well kept and the goats are communally managed. The farmer group with goat population and membership are shown in Table 1.

Table I CBBP farmer groups visited and organized

\begin{tabular}{llll}
$\begin{array}{l}\text { Farmer } \\
\text { Group }\end{array}$ & County & $\begin{array}{l}\text { Goat } \\
\text { Population }\end{array}$ & Membership \\
\hline Kukatonon & Bong & 53 & 23 (10 male and I3 female $)$ \\
Kergeamah & Bong & 19 & 13 (7 male and 6 female $)$ \\
Yarwaseh & Nimba & 25 & 12 (10 male, 2 female $)$ \\
KpiekPoah & Nimba & 16 & 24 (14 male, 10 female $)$ \\
Neepuah & Grand Bassa & 46 & 15 (10 male, 5 female $)$ \\
Morris Town & Grand Bassa & 70 & 20 (13 male, 7 female $)$ \\
\hline
\end{tabular}

\section{Off the field experience}

During the deliberations on the importance of quality in goats and how quality must be preserved and multiplied as opposed to the selling of good animals that could reproduce and give out good offspring for sale and for breeding, one farmer remembered his experience with his Rooster, that was very productive and of higher quality than others that he sold to finance an emergent situation at that time, yet now he regrets because the rooster he has currently is performing very poorly. Figure $1 \&$ Figure 2 show farmer groups visited and group discussions.

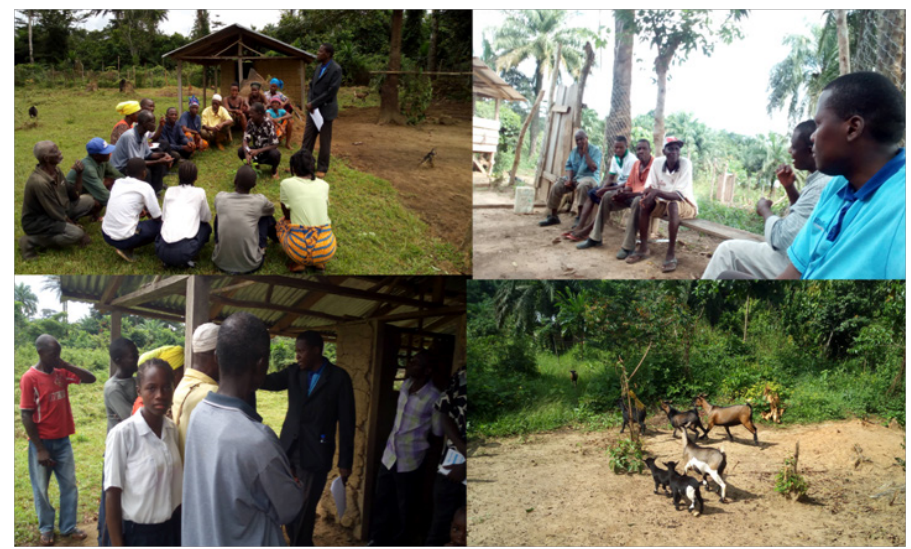

Figure I Farmer field visits. Clockwise: Kukatonon farmer group discussion; Kergeamah farmer group discussion; Grazing goats at Kergeamah goat shelter; Kukatonon farmers engaging the team.

\section{Selection of CBBP farmers}

Haile et al. ${ }^{6}$ proposed selection criteria for use in recruiting rural livestock keepers into a community based breeding programme. The selection criteria adopted here borrows much from the recommendation of the latter guidelines while adopting case specific criteria to suit local conditions. In this exercise, a simple evaluation tool was developed, namely, the CBBP Recruitment Matrix (CRM). 


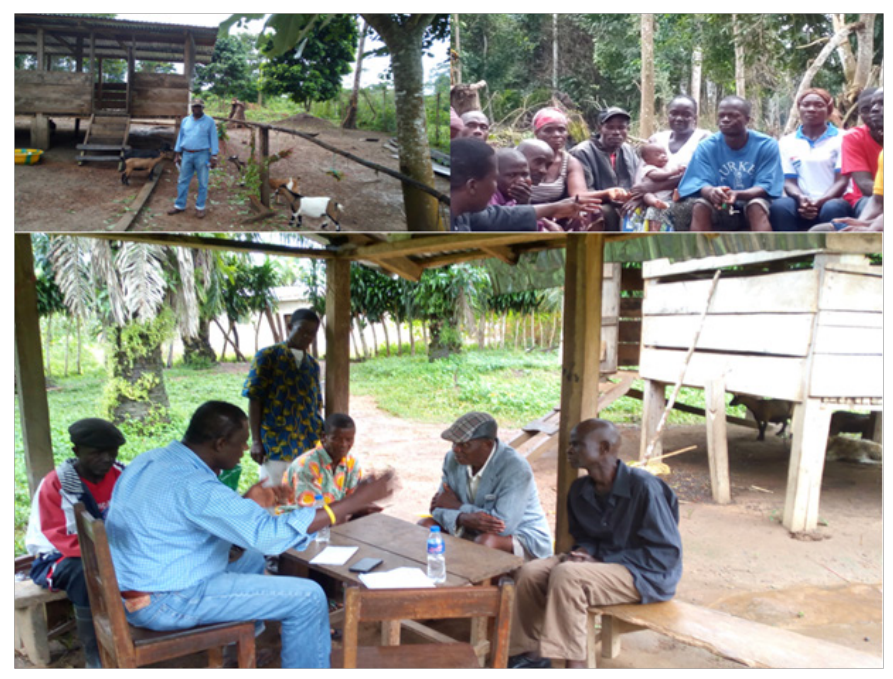

Figure 2 Farmer field visit: Above; National Project Coordinator at Kpiek Poah goat shelter; Farmers concentrating on focus group discussions: Below; Group discussions at Yawaseh.

The tool is composed of a table with various criteria depicting both necessary and important featured of a farmers' group. The criteria were weighed wither to have a strength of 1 denoting Necessary, or 0.5 denoting Important but not Necessary. Farmer groups were evaluated on whether they exhibited the criteria $(1=$ Yes $))$ or not $(0=\mathrm{No})$ and the total score added objectively. Table 2 represents the CRM tool. The figures in column after the criteria denote the weight of the criterion. The CRM tool was designed to reduce bias in selection of CBBP farmers so as to allow the farmers to appreciate inherent qualities that are necessary for breeding programs. It is expected that farmers will learn from the information to improve their score. The results of this particular analysis are to be fed back to the farmers at the Training Workshop and during follow-up visits. The 5-day training workshop was scheduled from the $17^{\text {th }}$ to the $21^{\text {st }}$ of October 2016 .

\section{The CBBP training workshop}

On the $17^{\text {th }}$ October 2016 , the CBBP stakeholders comprising of selected farmer groups, CARI staff and FAO technical team converged for the CBBP training workshop with the main objective being consultative development of the CBBP operating system and the Strategic plan. It was envisaged that the farmers would consultatively develop the breeding objectives traits for the Goat breed of choice, identify the measurable selection criteria characters and operationalize a simple genetic evaluation, selection and mating system. The training workshop included presentation on Goat Management, production, nutrition and feeding, breeding and selection, health and disease management, performance recording and record keeping and value chain and marketing. Practical exercises were on routine husbandry practices, disease identification, goat evaluation and selection, mineral lick production and identification (ear tags and notching). Practical training by famers in goat evaluation and mineral lick preparation are shown in Figure 3. The Goat farmers agreed that their Goat of Choice; the West African Dwarf Goat is mainly a meat goat. The pillars sustaining production were classified as; management, feeding, health and breeding. The farmers agreed that all other pillars except breeding could be introduced by human intervention. Breeding involved, to quote one farmer "in-built God given quality" which the participants were able to discover are called genes (genetics) and so would require special techniques to preserve, multiply and conserve. The farmers agreed that they most often sold their best animals therefore squandering quality and loosing production in their farms due to lack of knowledge. The farmers were made to understand that mating and breeding are not one and not the same; mating results to reproduction but breeding results to genetic improvement. The concept of choice, because not all animals are the same, was articulated with participation from the plenary. The farmers agreed that quality to them would mean heavy animals (indicating meat) and more kids per doe (indicating reproductive efficiency). These discussions set the stage for the building of a common platform of action towards harnessing the benefits of goat production through breeding, i.e. the development of the Community Based Breeding Program.

Table 2 CBBP Recruitment Matrix (CRM)

\begin{tabular}{|c|c|c|c|c|c|c|c|}
\hline \multirow{2}{*}{ Criteria weight } & & \multicolumn{2}{|l|}{ Bong } & \multicolumn{2}{|l|}{ Nimba } & \multicolumn{2}{|c|}{ Grand-Bassa } \\
\hline & & Kukalnnon & Kergermah & Kpiekpoah & Yawaseh & Neepuahn & MorrisTown \\
\hline Group organisation & I & 1 & 1 & 1 & 1 & I & I \\
\hline participating in antagonistic projects & -3 & 0 & 0 & 0 & 0 & 0 & I \\
\hline Presence of community leaders in the group & I & 1 & 0 & 1 & 0 & 0 & 0 \\
\hline willingto commit and invest time and resources & 1 & 1 & 1 & 1 & 1 & 1 & I \\
\hline Availability for training/capacity building & 0.5 & 1 & 1 & 1 & 1 & I & I \\
\hline Farm accessibility & 1 & 1 & 0 & 1 & 1 & 0 & $\mathrm{I}$ \\
\hline Market Access & 0.5 & 1 & 0 & 1 & 1 & I & I \\
\hline Support from government or NGOs & 0.5 & 0 & 0 & 0 & 0 & 0 & I \\
\hline Animal Population size & 1 & 1 & 1 & 0 & 0 & 1 & I \\
\hline Market orientation & 0.5 & 0 & 1 & 0 & 0 & 0 & I \\
\hline Feeding regime & 1 & 0 & 1 & 0 & 0 & I & I \\
\hline Health care & 0.5 & I & I & 0 & 1 & 0 & I \\
\hline
\end{tabular}


Table Continued.

\begin{tabular}{|c|c|c|c|c|c|c|c|}
\hline Criteria weight & & Bong & & Nimba & & Grand-B & \\
\hline Communication & I & I & I & I & I & I & $\mathrm{I}$ \\
\hline Group cooperation & I & 1 & I & I & I & I & 1 \\
\hline Total Score & & 8.5 & 7.5 & 7 & 6.5 & 7 & 6.5 \\
\hline Remarks & & Selected & Reserved & Selected & Reserved & Selected & Reserved \\
\hline
\end{tabular}

Source: Rewe \& Karnuah ${ }^{7}$

Key: Criteria Score weight: $0.5=$ important or I=very important; I=Yes: Present, $0=$ No: Absent; reflects status of group with respect to criteria; Selected: Recruited for piloting CBBP; Reserved: Earmarked for out-scaling

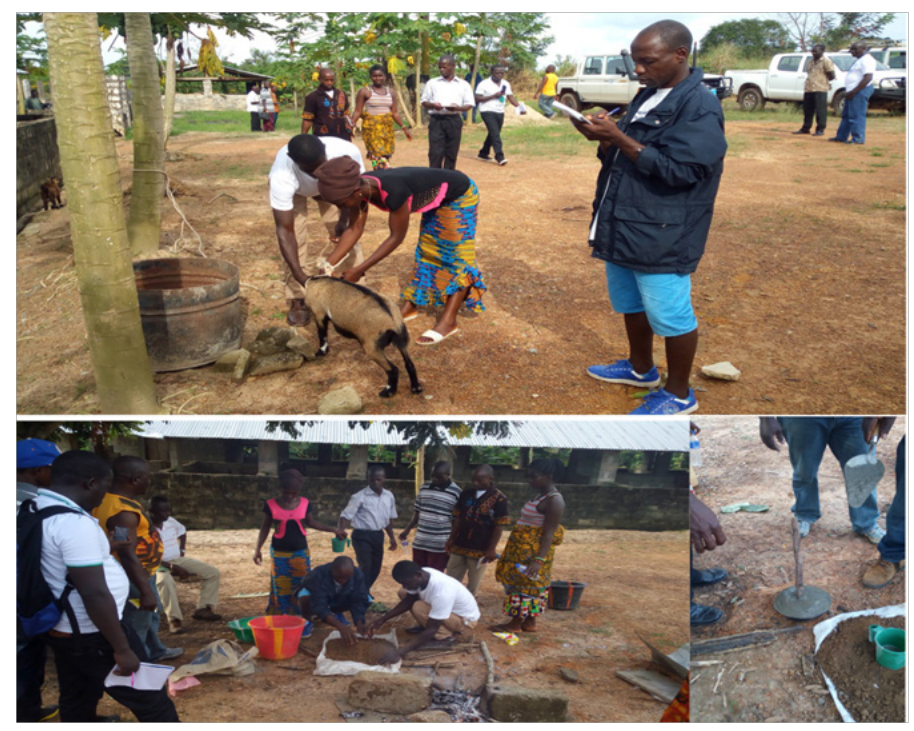

Figure 3 Goat evaluation and mineral lack preparation by CBBP farmers at CARI, Liberia.

\section{Breeding objectives}

The Breeding objectives for the CBBP were developed by the farmers through participatory discussions and demonstrations and resulted as follows:

\section{Goat Mature Weight}

\section{Reproductive efficiency}

The selection criteria traits to be recorded were agreed upon as:

i. Birth weight - to be measured using a simple weighing scale

ii. Weaning weight - to be measured using a simple weighing scale

iii. Kidding rate (twinning, triplet, quadruplet) - measured by observation

iv. Body conformation: Udder confirmation, Scrotal size - measured by observation, physical structure, appearance and size

v. Mature body weight - Measured by heart/girth meter

vi. Good feeder - feeding behavior

vii. Good mother - kid care and suckling

\section{Goat value chain}

a) A very important task in the training included the analysis of the meat goat value chain. The workshop participants, goat famers, were organized into an "innovation platform" and ideas were shared on how to develop an efficient meat goat value chain to support the CBBP long-term objectives. The options discussed towards building a working model for the meat goat value chain were;

b) Developing a regular goat auction market

c) Developing a local butchery

d) Developing a goat meat pepper soup business

e) Developing a refrigerated slaughter house

The participants were finally introduced to Strategic planning in the simple way possible, and a task given to them to develop a shortterm strategic plan to kick-start the work of the CBBP. The farmers agreed to present a plan during the closing of the workshop. The strategic plan was later presented by the farmers and they received constructive criticisms that the plan should actually be achievable in short term. It was agreed that the formation of the breeding flocks among the current group of farmers selected to pilot the CBBP be prioritized, to allow for identification and recording before a full scale farmer recruitment exercise commences. The 5-day workshop ended with speeches from MOA, CARI and FAO Officials followed by certification of the farmers for their participation.

\section{On-farm selection trials}

To verity the effectiveness of the one week training workshop, on-farm selection field trials were conducted. The farmer group was tasked with the responsibility of forming a nucleus flocks. The process of recruiting the nucleus Buck and five nucleuses Does was guided and witnessed by the National Project Coordinator and International Consultant. The farmers used their cards with drawings of the selection criteria to communicate the trait levels to all participating members. The main strategy was live goat evaluation with memory-based records as additional information. The farmers were then required to select the nucleus Buck and Does using ear tags to identify. It was recommended that kids born nucleus Does must be identified and their records taken. Initially these kids will be identified using colored neck strains in reference to their Does, since only one Buck will be in use. Eventually, all the nucleus flocks will be ear tagged. The animal registers as well as the production and reproduction records keeping materials were introduced and practiced with the farmers. All goats in 
the flock (nucleus and base) are to be recorded in the animal register. The production and reproduction record sheets were prepared and given to the framers for recording the kids expected from the nucleus Does. The nucleus Buck and Does selection process by the farmers.

\section{The breeding, production and marketing systems}

Breeding system: It was observed that all farmers have the West African dwarf goat. They practiced pure-breeding based on the West African dwarf goat under natural mating.

Production system: The farmer groups practiced semi-intensive system, with night shelter and day grazing/browsing for goats. Goats are also supplemented at the shelter from cuttings of different browse feed (cut-and-carry). The health care support services are provided by the locally trained community health workers with assistance from the MOA County Livestock Officer. A typical goat shelter is shown in Figure 4.

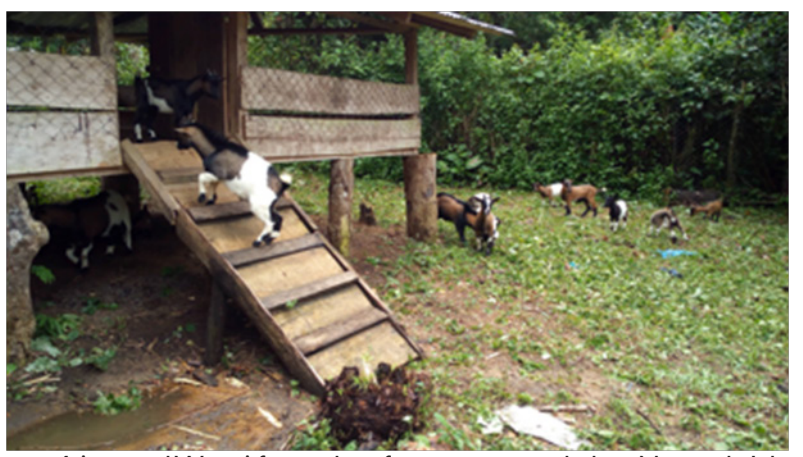

Figure 4 A typical West African dwarf goat at a goat shelter, Neepuah, Liberia.

Marketing system: The markets are traditional systems, mostly reliant on seasonal markets related to festivals and cultural events. The CBBP has an objective is to develop a regular market for meat goats through the development of a meat goat value chain. The flow chat of CBBP operational system is shown in Figure $5 .^{7}$

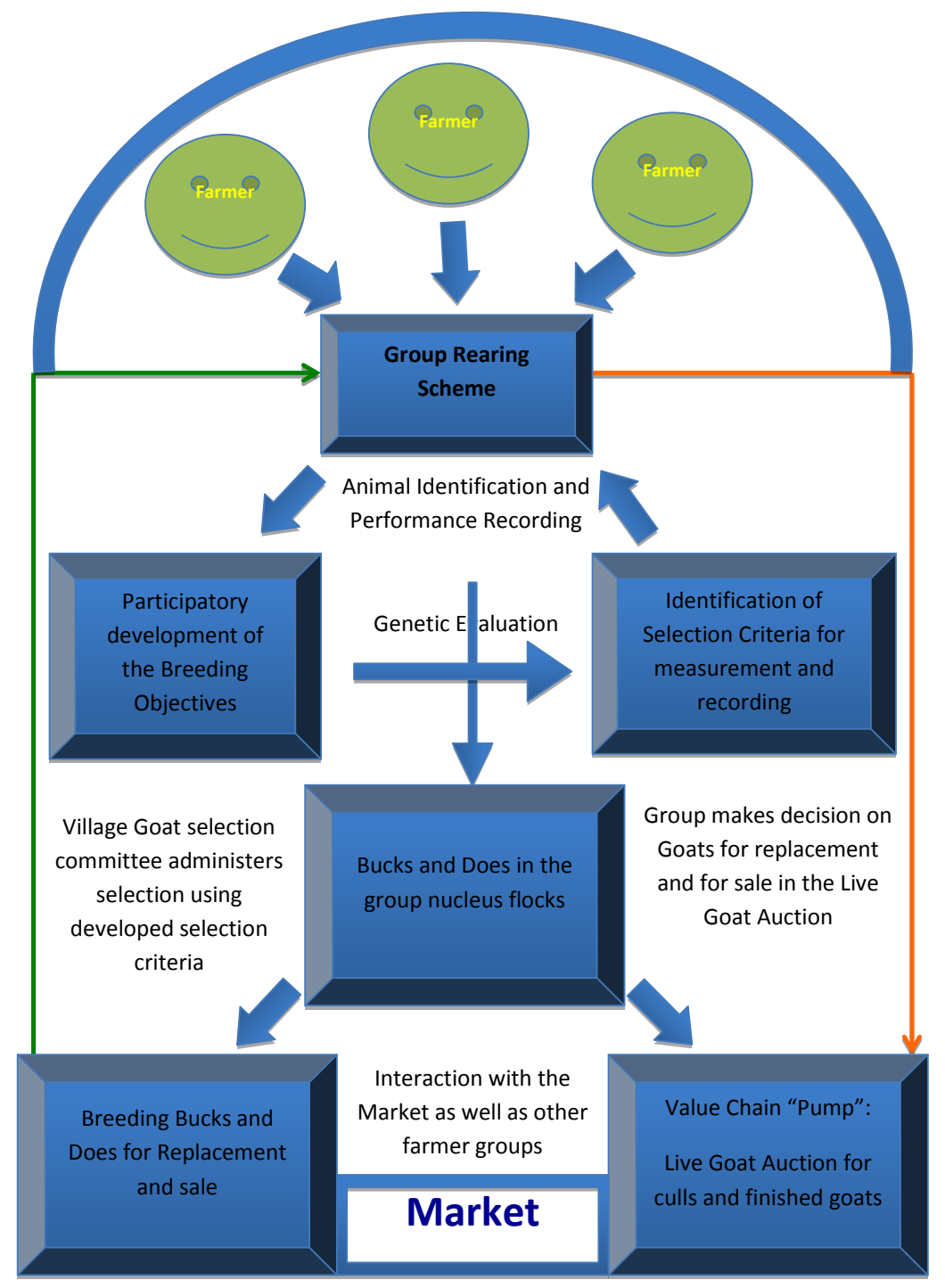

Figure 5 The CBBP operating system. 


\section{Conclusion}

The pilot project of CBBP was successfully established among goat farmers' groups in three Counties in Liberia. The CBBP will bring improved management of goat genetic resources leading to increased productivity and greater genetic diversity. Lessons learned from the CBBP will eventually benefit other similar Counties and communities that will adopt the CBBP. The sustainability of the CBBPs would require appreciation of strength, weaknesses, and threats, which are briefly highlighted herein. The SWOT analysis is informed by the National Strategy and Action for Animal Genetic Resources (AnGR) Report of Liberia.

\section{Strengths}

i. Well-built goat shelters

ii. Group goat rearing schemes

iii. Farmers' organizations

\section{Weaknesses}
A. Illiteracy levels
B. Infrastructure (market access)

\section{Opportunities}

a. Goat nucleus breeding program facility at CARI, potential for central nucleus flocks

b. Relationship with CARI, Centralized recording system possible

c. Meat goat value chain development

\section{Threats}

A. Cultural rights on goat ownership and use

B. Profit and loss sharing

C. Compensation mechanisms (in case of goat mortality among group farmers)

\section{Recommendations}

a. The CBBP should commence gradually as the way the first group was rolled out with constant monitoring and evaluation mechanisms.

b. The CBBP as a pilot exercise should be supported to develop capacity for out-scaling. c. CARI should take on the responsibility of data-banking, by collecting regularly records from group farmers for computer based animal recording system.

d. The CBBP model should be replicated for other Counties towards engaging all goat farmers in Liberia

e. The CBBPs in different County should be encouraged and supported to join a National Breeding Program in future with centralized recording.

f. Animal Breeding post-graduate program should be launched in Liberia to encourage partnership with Universities and CBBPs.

\section{Acknowledgements}

i. The Food and Agriculture Organization of the United Nations (FAO)

ii. Central Agricultural Research Institute (CARI), Liberia

iii. Pwani University, Kilifi, Kenya

\section{Conflict of interest}

The authors declared that there is no conflict of interest.

\section{References}

1. Andrews L, A situational analysis of livestock production in Liberia: A case study of Nimba, Bong and Montserrado counties. Kenya: University of Nairobi; 2012.

2. FED. Food and Enterprise Development (FED) program for Liberia supported by USAID. Fiscal year 2014 annual report. Liberia: DAI; 2014.

3. The Daily Observer. Careysburg Slaughter House - A Good Sign Of Things To Come. News Report, 7th September, 2016.

4. ESGPIP. Technical bulletin No. 42. A practical guide on village-based sheep and goat cooperative breeding schemes. Technical Bulletin No. 42. 2011

5. Mueller JP, Rischkowsky B, Haile A, et al. Community-based livestock breeding programs: essentials and examples. J Anim Breed Genet. 2015; $132: 155-168$

6. Haile A, Wurzinger M, Mueller J, et al. Guidelines for Setting up Community-based Sheep Breeding Programs in Ethiopia: Lessons and experiences for sheep breeding in low-input systems. ICARDA-tools and guidelines. 2011. 1 p.

7. Karnuah AB, Rewe T. CBBP recruitment matrix. Liberia: Central Agricultural Research Institute (CARI); 2016. 